\title{
Efeito da utilização de diferentes diluidores para a produção in vitro de embriões bovinos
}

\author{
[Effect of different bovine semen extenders on in vitro development of bovine embryos] \\ R.B. Prado, M.B. Koivisto, J.T. Carreira, S.H.V. Perri, L.H. Rodrigues, H. Atique Netto, \\ T.L.G. Torregrossa, W.R.R. Vicente, M.A.R. Feliciano*
}

Faculdade de Medicina Veterinária de Araçatuba - UNESP

\begin{abstract}
RESUMO
Objetivou-se avaliar as características morfológica e funcional do sêmen bovino congelado comparandose a eficácia de dois diferentes diluidores. O ejaculado de quatro touros foi dividido em duas partes iguais, uma submetida ao diluidor Tris e gema de ovo (A) e outra ao diluidor à base de lecitina de soja (Andromed $($ ) (B). No experimento I, cinco palhetas dos diluidores A e B de cada touro foram descongeladas e avaliadas quanto à motilidade, vigor, concentração, morfologia espermática e teste de termor-resistência lento. Foram feitas, ainda, avaliação da integridade de membranas, por meio da associação das sondas iodeto de propídio, isotiocionato de fluoresceína - Pisum sativum e carbocianina catiônica lipofílica, e avaliação funcional da membrana plasmática com teste hiposmótico. A avaliação da integridade da cromatina foi realizada pelo método de coloração com laranja de acridina. No experimento II, o sêmen com os diferentes diluidores foi utilizado na fecundação in vitro, sendo observadas taxas de clivagem e desenvolvimento embrionário in vitro. Em relação aos resultados obtidos, apenas a porcentagem de espermatozoides no sêmen congelado foi discretamente maior com o diluidor A, concluindo-se que o diluidor composto por lecitina de soja pode substituir o composto por Tris e gema de ovo, respeitando-se as variações individuais de cada touro utilizado no presente experimento.
\end{abstract}

Palavras-chave: bovino, lecitina de soja, gema de ovo, diluidor, embriões, fecundação in vitro e sêmen

\begin{abstract}
The goal of this study was to evaluate the protective effect of egg yolk compared with a soybean lecithinbased extender on morphologic and functional characteristics of frozen bovine semen. The ejaculate of four bulls was divided into two equal parts, one diluted with egg-yolk-Tris extender (A) and the other with a soy-lecithin based extender (Andromed $(B)(B)$. In experiment I, five straws of extender $A$ and $B$ from each bull were thawed and assessed regarding motility (subjective and computerized analysis), vigor, concentration, sperm morphology and slow thermoresistance (STR), evaluation of membrane integrity through association of propidium iodite probes (PI), fluorescein isotiocianate - Pisum sativum (FITC$P S A)$ and lipophilic cationic carbocyanine (JC-1) and functional evaluation of the plasmatic membrane through Hyposmotic Swelling Test (HOST). An evaluation of chromatin integrity was performed with the acridine orange staining procedure. In experiment II, the frozen semen with different extenders was used for in vitro fertilization (IVF), analyzing cleavage rates and in vitro embryo development. No statistical difference between extenders was identified, suggesting that the soy lecithin extender may substitute eggyolk-Tris extender, considering the individual variations of each bull used in this experiment.
\end{abstract}

Keywords: bovine, soy lecithin, egg yolk, extender, embryos, in vitro fertilization and semen

Recebido em 19 de maio de 2011

Aceito em 22 de maio de 2012

*Autor para correspondência (corresponding author)

E-mail: marcusfeliciano@yahoo.com.br 


\section{INTRODUÇÃO}

Com a descoberta do uso do glicerol como crioprotetor, o armazenamento de sêmen foi revolucionado. Essa importante inovação possibilitou que os espermatozoides pudessem ser congelados por um período prolongado e depois usados com sucesso na inseminação artificial (IA) e, mais tarde, em programas de produção in vitro de embriões (PIV), permitindo uma melhora na seleção genética em bovinos (Aires et al., 2003).

A diluição do sêmen é imprescindível antes de submetê-lo à congelação, e os diluidores são utilizados com a finalidade de proteger os espermatozoides, oferecendo condições mínimas de sobrevivência no trato reprodutivo da fêmea para que ocorra a fertilização. A proteção oferecida durante as fases de desidratação, de congelação e a estabilização da bicamada lipídica dependem das substâncias que compõem o diluidor. Além disso, diluidores que contêm produtos de origem animal e vegetal podem trazer riscos de contaminação por bactérias ou outros microrganismos, sendo uma possível fonte de endotoxinas capazes de afetar a capacidade de fecundação dos espermatozoides (Bousseau et al., 1998)

Do ponto de vista sanitário, para a comercialização internacional do sêmen bovino, o uso de diluidores quimicamente definidos compostos de substâncias de origem vegetal é recomendado em relação aos diluidores tradicionais, compostos por substâncias de origem animal (Januskauskas et al., 2000).

A gema de ovo é um dos principais crioprotetores não penetrantes, e seu principal beneficio é fornecer uma fração LDL que previne a perda de fosfolipídios da membrana celular, aumentando, assim, a tolerância ao choque térmico e ao processo de congelação (Amirat et al., 2004). Esse composto apresenta como inconvenientes: ser passível de contaminação, prejudicando a capacidade de fecundação dos espermatozoides (Pagl et al., 2006); ser de difícil padronização (Wall e Foote, 1999); conter substâncias que podem inibir a atividade mitocondrial dos espermatozoides, diminuindo sua motilidade (Pace e Graham, 1974), e hormônios esteroides que podem diminuir a capacidade de fecundação dos espermatozoides (Muino et al., 2007).

Um dos primeiros diluidores disponíveis, compostos por substâncias de produtos não originados de animais, é o Andromed $\AA$, apresentando como composição o extrato de soja. Ele já foi testado por alguns pesquisadores (Muino et al., 2007), quando foi provada a viabilidade do uso desses para a congelação espermática (Janett et al., 2005). No entanto, outros autores não encontraram resultados positivos em relação à crioproteção espermática com o uso de diluidores livres de proteína animal (Nothling et al., 2007; Fukui et al., 2008).

Objetivou-se avaliar a proteção e a viabilidade oferecidas aos espermatozoides bovinos utilizando-se diluidor composto por proteína vegetal (extrato de soja), comparando-o com diluidor à base de gema de ovo, por meio de testes complementares e a produção in vitro de embriões (PIV)

\section{MATERIAL E MÉTODOS}

Foram utilizados quatro touros da raça Nelore em idade reprodutiva, mantidos em regime semiextensivo. Coletou-se, de cada animal, conteúdo seminal pelo método da vagina artificial. O ejaculado de cada touro foi dividido em duas partes iguais, adicionando-se o diluidor A (Tris e gema de ovo) para uma parte e o diluidor B (Andromed $®$ - lecitina de soja) para outra. Após acréscimo dos diluidores, o sêmen bovino foi resfriado, congelado e armazenado em nitrogênio líquido a $-196^{\circ} \mathrm{C}$, seguindo os procedimentos padrões da central de inseminação artificial. $\mathrm{O}$ estudo foi dividido em dois experimentos. No experimento I foram realizados testes complementares para avaliação espermática, e no experimento II foi realizada a PIV.

Para o experimento I, cinco palhetas de $0,25 \mathrm{~mL}$ dos diluidores $\mathrm{A}$ e $\mathrm{B}$ de cada touro foram descongeladas a $35^{\circ} \mathrm{C}$ por 30 segundos e transferidas para tubos de hemólise com tampa de látex mantidos em banho-maria a $37^{\circ} \mathrm{C}$. Imediatamente após a descongelação, foram avaliadas: motilidade progressiva $\mathrm{e}$ retilínea subjetiva e computadorizada, vigor espermático (0-5), concentração espermática (espermatozoides/mL), morfologia espermática, 
e foi realizado o TTL (teste de termorresistência lento) (incubação do sêmen em banho-maria a $37^{\circ} \mathrm{C}$ por três horas). As avaliações de motilidade subjetiva, vigor, porcentagem de acrossoma intacto (PIA) e integridade do DNA foram repetidas após o TTL.

Para avaliação das membranas acrossomal, citoplasmática e mitocondrial, foi utilizada a associação de sondas fluorescentes PI (iodeto de propídio), FITC-PSA (isotiocionato de fluoresceína - Pisum sativum e carbocianina) e JC-1 (catiônica lipofílica). O HIPO (teste hiposmótico) foi utilizado como avaliação complementar da funcionalidade da membrana plasmática.

A motilidade foi determinada pela estimativa visual da porcentagem de células em movimento e também pela redução do campo pelo diafragma, com contagem de células com movimento progressivo retilíneo e de células imóveis. O vigor foi avaliado de acordo com a velocidade do movimento progressivo dos espermatozoides, e classificado de 0 a 5 , sendo 0 o mais lento e 5 o mais rápido (CBRA, 1998). Tanto a motilidade subjetiva quanto o vigor foram repetidos após a realização do TTL.

A avaliação da integridade da cromatina foi realizada pela coloração com AO (acridine orange). Para cada esfregaço, foram contadas 200 células, as quais foram classificadas de acordo com Tejada et al. (1984), sendo que as células com emissão de fluorescência verde foram consideradas normais, ou seja, com cromatina íntegra, enquanto as células com emissão de fluorescência vermelha, laranja ou amarela, distribuída de forma regular ou irregular no interior da cabeça, foram consideradas anormais, indicando desnaturação total ou parcial da cromatina. A avaliação da integridade da cromatina foi repetida logo após a realização do TTL.

Para a análise computadorizada do movimento espermático (CASA - HTMA-IVOS 12.3 Hamilton Research ${ }^{\circledR}$ - Beverly, M.A., U.S.A.), utilizou-se o hardware IVOS ("Integrat Visual Optical System" - Sistema Visual de Integração Óptica), versão 12.3, da empresa "Hamilton Thorne Biosciences" $($, constituído pelo "Software Animal Breeders", que é configurado com "setup", sendo recomendado pelo fabricante para touros. Avaliaram-se: VAP (velocidade de trajeto), VSL (velocidade linear), VCL (velocidade curvilinear), ALH (amplitude de batimento de cabeça), MT (motilidade total), MP (motilidade progressiva) e RAP (porcentagem de espermatozoides rápidos) (Sousa, 2002).

Para a avaliação da concentração espermática, realizou-se a contagem em câmara de Neubauer à microscopia de contraste de fase (200x), como descrito em CBRA (1998).

Ao se avaliar a morfologia espermática, utilizouse para a contagem das anormalidades espermáticas a técnica de câmara úmida, realizada de acordo com a classificação preconizada por Blom (1973), e o resultado por amostra foi dado em porcentagem.

Para o teste de termorresistência lento, a motilidade e o vigor espermáticos foram reavaliados. A PIA foi avaliada na mesma amostra em que se observou a presença do bordo apical sob microscopia de interferência diferencial de fase - DIC (1000x), diferenciando espermatozoides com acrossoma intacto ou não (Herman et al., 1996).

A integridade das membranas espermáticas foi avaliada pela associação de corantes fluorescentes PI (28707-5, Sigma®), FITC-PSA (L-0770, Sigma®) e JC-1 (T3168, Molécula Probes®), conforme o protocolo utilizado por Arruda e Celeghini (2003). Foram contadas 200 células e classificadas de acordo com a fluorescência emitida por cada sonda utilizada (PI, FITC-PSA e JC-1), as quais resultaram em oito categorias segundo Carreira (2008).

Para o HIPO, as células foram classificadas quanto à presença ou não de cauda dobrada ou enrolada, e o resultado foi determinado em porcentagem, efetuando-se o cálculo pela fórmula: HIPO $(\%)=(\%$ de alterações na região da cauda após teste HIPO) - (\% de alterações na região da cauda dos espermatozoides antes do teste HIPO).

Para o experimento II (produção in vitro de embriões), uma palheta dos diluidores A e B de cada touro foi utilizada na PIV, realizando-se oito repetições por amostra, sendo utilizados 25 oócitos em cada repetição. Os oócitos com cumulus compacto, provenientes de ovários de 
carcaças do abatedouro, possuindo pelo menos três a quatro camadas de células e citoplasma de granulação homogênea e aspecto esférico, foram selecionados para a maturação in vitro (MIV). Os oócitos com cumulus expandido, desnudos ou com citoplasma muito claro e alterações de formato foram descartados.

Após a maturação dos oócitos, que ocorreu em estufa a $38,5^{\circ} \mathrm{C}$, com $5 \%$ de $\mathrm{CO}_{2}$ em ar e umidade relativa de $99 \%$ por $24 \mathrm{~h}$, iniciaram-se o preparo do sêmen e a fecundação in vitro (FIV). A descongelação do sêmen foi realizada a $35^{\circ} \mathrm{C}$ por 30 segundos. Em seguida, os espermatozoides vivos foram separados do diluidor por sedimentação, em gradiente descontínuo. O sedimento foi diluído uma vez em solução de $1 \mathrm{mg}$ de heparina sódica/mL em meio Talp-sêmen e incubado a $38,7^{\circ} \mathrm{C}$ por 15 minutos. Após avaliação da motilidade progressiva e da concentração espermática, o número de espermatozoides foi ajustado para $25 \times 10^{6} / \mathrm{mL}$. Aproximadamente $100 \times 10^{3}$ espermatozoides foram adicionados a cada gota de $100 \mu \mathrm{L}$ de meio FIV designado a cada grupo experimental.

A fecundação foi realizada em estufa a $38,5^{\circ} \mathrm{C}$, contendo $5 \%$ de $\mathrm{CO}_{2} \mathrm{em}$ ar atmosférico e umidade relativa de $99 \%$ por 24 horas.

Após o cultivo in vitro (CIV) de zigotos, as gotas de CIV foram observadas para cálculo da taxa de clivagem (zigotos) e da taxa de embriões (blastocistos) no dia dois e no dia sete, respectivamente (sendo que o dia zero foi considerado o dia da FIV). Tanto a taxa de clivagem como a de embriões foram calculadas a partir do número de oócitos inseminados. A taxa de eclosão foi avaliada no dia nove e foi calculada a partir do número de blastocistos obtidos no dia sete.

As variáveis motilidades subjetiva e computadorizada, vigor, integridade da cromatina, do acrossoma, da membrana plasmática e potencial mitocondrial foram analisadas pelo teste de Wilcoxon, e a porcentagem de clivagem, de embriões e de eclosão foi submetida à análise de variância (ANOVA), com médias comparadas pelo teste de Tukey, utilizando-se programa computacional "Statistical Analysis System" (SAS, 2004), com nível de significância de $5 \%$.

\section{RESULTADOS E DISCUSSÃO}

A análise da motilidade espermática subjetiva (microscopia de contraste de fase), do vigor e da integridade da cromatina (LA) foi realizada em todas as amostras de sêmen após a descongelação (zero hora) e após a realização do TTL (três horas) para ambos os diluidores. $\mathrm{Na}$ Tab. 1 encontram-se os valores médios das características analisadas, não sendo verificada diferença significativa $(\mathrm{P}>0,05)$ para ambos os grupos avaliados nos diferentes tempos (zero hora e três horas) e entre os tempos de avaliação.

Tabela 1. Valores médios (x), desvio-padrão (s) e mediana (Md) para motilidade, vigor e DNA, estudados no sêmen congelado de quatro touros com o diluidor A (Tris e gema de ovo) e o diluidor B (Andromed® - lecitina de soja)

\begin{tabular}{lccccc}
\hline & \multicolumn{2}{c}{ Diluidor A } & \multicolumn{2}{c}{ Diluidor B } & \multirow{2}{*}{ Variáveis } \\
\cline { 2 - 5 } & $\mathrm{x} \pm \mathrm{s}$ & $\mathrm{Md}$ & $\mathrm{x} \pm \mathrm{s}$ & $\mathrm{Md}$ & $\mathrm{p}^{(1)}$ \\
\hline Motilidade 0h (\%) & $63,8 \pm 7,5$ & 65,0 & $55,0 \pm 5,8$ & 55,0 & 0,250 \\
Vigor 0h (0-5) & $3,3 \pm 0,6$ & 3,3 & $3,4 \pm 0,5$ & 3,3 & 1,000 \\
DNA lesado 0h (\%) & $1,0 \pm 0,0$ & 1,0 & $1,0 \pm 0,0$ & 1,0 & 1,000 \\
Motilidade 3h (\%) & $57,5 \pm 9,6$ & 55,0 & $48,8 \pm 8,5$ & 47,5 & 0,125 \\
Vigor 3h (0-5) & $2,9 \pm 0,3$ & 3,0 & $3,0 \pm 0,4$ & 3,0 & 1,000 \\
DNA lesado 3h (\%) & $1,0 \pm 0,0$ & 1,0 & $1,0 \pm 0,0$ & 1,0 & 0,500 \\
\hline
\end{tabular}

Teste de Wilcoxon $(\mathrm{p}>0,05)$.

Esses resultados corroboram outros estudos que avaliaram a motilidade espermática subjetiva do sêmen bovino (Amirat et al., 2004) criopreservado com diluidores livres de proteína animal, compostos por gema de ovo logo após a descongelação. Cabe ressaltar que, para a avaliação da motilidade espermática do sêmen bovino, a literatura apresenta dados divergentes. Vários pesquisadores observaram um desempenho melhor com o diluidor à base de 
lecitina de soja quando comparado ao Tris e à gema de ovo (Dell'Aqua Júnior et al., 2007).

Os resultados encontrados na literatura correlacionando motilidade subjetiva espermática aos diferentes diluidores e à fertilidade de uma amostra seminal pósdescongelação são divergentes. Garner et al. (1997) ponderam que, na avaliação visual, ocorre uma tendência de subestimar a porcentagem de espermatozoides móveis. Assim, é desejável a realização de testes específicos da função espermática, como avaliação computadorizada do sêmen, coloração das estruturas espermáticas por sondas fluorescentes, HIPO e PIV (Tartaglione e Ritta, 2004).

Após a realização do TTL, no presente estudo, observou-se uma queda gradual da motilidade espermática subjetiva para ambos os diluidores, confirmando as observações de Aires et al. (2003). Sugere-se que essa queda possa ser decorrente da perda de componentes intracelulares ou de lesões estruturais na cauda dos espermatozoides.

Em relação aos resultados observados para vigor espermático após a descongelação e após o TTL, eles permaneceram dentro dos níveis aceitáveis (CBRA, 1998): escore 3 (escala de 1 a 5). Para ambos os diluidores, houve uma redução do vigor após a realização do TTL.

Os resultados do presente estudo sugerem que os espermatozoides bovinos criopreservados não apresentavam desnaturação da cromatina, independentemente do tipo de diluidor utilizado. O processo de criopreservação gera aumento da produção de radicais livres e redução da capacidade antioxidante, provocando danos, inicialmente à membrana plasmática (Upreti et al., 1998), podendo se estender à cromatina (Thomson et al., 2009).

No DNA, os danos acontecem principalmente pela ação do radical hidroxila, que tem preferência pela ligação à guanina. Esta ligação modifica a base, podendo gerar mutações (Comhaire et al., 2000).

Ao avaliar a PIA, o resultado obtido para o diluidor A foi de 50,3\% e para o diluidor B de $53,4 \%$ ( $p>0,05)$. A avaliação da porcentagem de acrossomas íntegros consiste em teste complementar importante, já que os espermatozoides serão submetidos a temperaturas mais elevadas, como, por exemplo, a do ambiente uterino. Sem a presença do capuz cefálico, eles se tornarão inaptos e não ocorrerá à reação acrossomal, fundamental para a fertilização.

Os valores médios da motilidade total (MT), motilidade progressiva (MP) e espermatozoides rápidos (RAP) obtidos com $\mathrm{o}$ diluidor $\mathrm{A}$ $(69,5 \% \pm 12,9 ; \quad 34,5 \% \pm 10,2$ e $53,3 \% \pm 14,8$, respectivamente) e com o diluidor B $(57,7 \% \pm 7,8$; $25,5 \% \pm 3,1 ; 47,2 \% \pm 6,2$, respectivamente) não foram estatisticamente diferentes $(\mathrm{P}>0,05)$. Os valores médios de VAP (velocidade de trajeto), VSL (velocidade linear), VCL (velocidade curvilinear), ALH (amplitude de batimento de cabeça) obtidos com o diluidor A $(77,4 \mu \mathrm{m} / \mathrm{s} \pm 9,1$; $57,0 \mu \mathrm{m} / \mathrm{s} \pm 7,0 ; \quad 139,0 \mu \mathrm{m} / \mathrm{s} \pm 14,6 ; \quad 7,0 \mu \mathrm{m} / \mathrm{s} \pm 0,3$, respectivamente) e para $\mathrm{O}$ diluidor $\mathrm{B}$ $(89,7 \mu \mathrm{m} / \mathrm{s} \pm 5,7 ; 61,1 \mu \mathrm{m} / \mathrm{s} \pm 5,5 ; 171,9 \mu \mathrm{m} / \mathrm{s} \pm 10,8 ;$ $8,1 \mu \mathrm{m} \pm 0,38$, respectivamente) também não diferiram estatisticamente $(\mathrm{P}>0,05)$ entre os diluidores. Em relação à motilidade espermática, os resultados encontrados neste experimento (não se observou diferença significativa entre os tratamentos) diferem dos achados de Janett et al. (2005), que relatam o aumento da motilidade com a utilização de diluidor à base de lecitina de soja ao ser comparado com o composto à base de gema de ovo. Os valores médios apresentados para VAP, VSL, VCL e ALH no presente estudo corroboram os resultados obtidos por Gil et al. (2000). Diversas pesquisas descrevem que a porcentagem elevada de VAP, VSL, VCL e ALH, encontrada na análise do sêmen pelo sistema CASA, condiz com a hiperativação espermática. A hiperativação é considerada um componente do processo de capacitação.

A análise da morfologia espermática, classificada em defeitos maiores e menores de acordo com Blom (1973), foi realizada em todas as amostras logo após a descongelação. O tipo de diluidor não interferiu $(p>0,05)$ na porcentagem de defeitos maiores, menores e totais, contrariando Thun et al. (2002), que observaram efeito do tipo de diluidor na morfologia espermática e concluíram que o composto à base de Tris e gema de ovo apresentou uma quantidade maior de defeitos maiores, e o diluidor à base de lecitina de soja de defeitos menores. 
Não houve diferença significativa entre a porcentagem de acrossoma íntegro, a membrana plasmática íntegra e a presença de potencial mitocondrial quando se compararam os diluidores A e B (Tab. 2). Esses resultados corroboram estudos que avaliaram o efeito de diluidores à base de gema de ovo e à base de lecitina de soja na proteção à membrana plasmática de espermatozoides bovinos (Janett et al., 2005).

Tabela 2. Valores médios (x), desvio-padrão (s) e mediana (Md) da integridade da membrana citoplasmática, da integridade do acrossoma e da presença de potencial mitocondrial, obtidos pela associação das sondas FITC-PSA, PI e JC-1, após descongelação e lavagem do sêmen congelado de quatro touros com o diluidor A (Tris e gema de ovo) e o diluidor B (Andromed®)

\begin{tabular}{|c|c|c|c|c|c|}
\hline \multirow[b]{2}{*}{ Variável } & \multicolumn{2}{|c|}{ Diluidor A } & \multicolumn{2}{|c|}{ Diluidor B } & \multirow[b]{2}{*}{$\mathrm{p}^{(1)}$} \\
\hline & $\mathrm{x} \pm \mathrm{s}$ & Md & $\mathrm{x} \pm \mathrm{s}$ & $\mathrm{Md}$ & \\
\hline Acrossoma íntegro (\%) & $36,2 \pm 5,2$ & 71 & $40,7 \pm 19,6$ & 81 & 0,625 \\
\hline Membrana íntegra (\%) & $25,0 \pm 22,8$ & 51 & $20,2 \pm 20,4$ & 36 & 0,625 \\
\hline Potencial mitocondrial (\%) & $24,2 \pm 29,4$ & 45 & $20,0 \pm 24,3$ & 41 & 0,625 \\
\hline
\end{tabular}

Teste de Wilcoxon $(\mathrm{P}>0,05)$.

Durante a leitura dos espermatozoides avaliados pelo HIPO, uma variedade de diferentes tipos de caudas enroladas e dobradas foi observada. As flexões observadas em graus diferentes nos filamentos do axonema da cauda podem ocorrer conforme a quantidade de água que penetra na membrana (Siqueira et al., 2007).

A porcentagem de espermatozoides reativos ao HIPO do sêmen congelado com o diluidor A $(57 \%)$ foi superior ao grupo do diluidor B
(43,5\%). Quando se compararam os valores médios entre os diluidores, não se verificou diferença significativa $(\mathrm{P}>0,05)$, corroborando os resultados obtidos por Gil et al. (2000).

Não se verificou diferença significativa para a taxa média de clivagem ( $\mathrm{P}>0,05)$ (Tab. 3), resultado esse que corrobora os obtidos por Nabiev et al. (2003) para comparação desses dois mesmos diluidores.

Tabela 3. Valores médios (x) e desvio-padrão (s) da \% de clivagem do sêmen congelado de quatro touros com o diluidor A (Tris e gema de ovo) e o diluidor B (Andromed $®$ - lecitina de soja)

\begin{tabular}{cccc}
\hline \multirow{2}{*}{ Touro } & \multicolumn{2}{c}{ Diluidor $(\mathrm{x} \pm \mathrm{s})$} & Total \\
\cline { 2 - 4 } & $\mathrm{A}$ & $\mathrm{B}$ & $67,50 \pm 8,23$ \\
$\mathrm{~A}$ & $63,67 \pm 7,20 \mathrm{abA}$ & $62,33 \pm 7,87 \mathrm{aA}$ & $68,83 \pm 8,84$ \\
$\mathrm{~B}$ & $75,00 \pm 7,97 \mathrm{aA}$ & $63,00 \pm 6,13 \mathrm{aB}$ & $68,67 \pm 8,88$ \\
$\mathrm{C}$ & $74,33 \pm 7,63 \mathrm{aA}$ & $70,00 \pm 6,07 \mathrm{aA}$ & $61,67 \pm 10,33$ \\
$\mathrm{D}$ & $53,33 \pm 5,61 \mathrm{bB}$ & $66,75 \pm 7,05$ & \\
\hline Total & $66,58 \pm 11,26$ & & \\
\hline
\end{tabular}

*\% de clivagem foi calculada pelo número de oócitos inseminados.

Coelho et al. (2000) obtiveram taxa média de clivagem mais baixa, ao utilizarem sêmen diluído e congelado com diluidor Tris e gema de ovo, quando comparada ao estudo presente $(54,50 \%$ e $66,58 \%$, respectivamente). Os diluidores A e B não interferiram na taxa de clivagem, contrastando com outras pesquisas que verificaram a influência do diluidor na taxa de clivagem (Lonergan et al., 1993).

Na Tab. 4 estão apresentados os valores médios e o desvio-padrão da porcentagem de embriões produzidos in vitro (calculada a partir do número de oócitos inseminados). Não foi encontrada diferença estatística $(\mathrm{P}>0,05)$ entre os diluidores testados.

A taxa média de embriões bovinos que atingem o estágio de blastocisto em meios tradicionais de cultivo foi em torno de 35\% (Brum et al., 2002), corroborando os resultados do presente experimento. 
Tabela 4. Valores médios (x) e desvio-padrão (s) da \% de blastocistos do sêmen congelado de quatro touros com o diluidor A (Tris e gema de ovo) e o diluidor B (Andromed® - lecitina de soja)

\begin{tabular}{|c|c|c|c|}
\hline \multirow[b]{2}{*}{ Touro } & \multicolumn{2}{|c|}{ Diluidor $(\mathrm{x} \pm \mathrm{s})$} & \multirow[b]{2}{*}{ Total } \\
\hline & $\mathrm{A}$ & B & \\
\hline A & $29,67 \pm 4,08 \mathrm{bB}$ & $37,33 \pm 4,32 \mathrm{abA}$ & $33,50 \pm 5,66$ \\
\hline B & $40,67 \pm 3,27 \mathrm{aA}$ & $29,67 \pm 4,46 \mathrm{bcB}$ & $35,17 \pm 6,85$ \\
\hline $\mathrm{C}$ & $37,00 \pm 5,33 \mathrm{aA}$ & $26,33 \pm 4,08 \mathrm{cB}$ & $31,67 \pm 7,18$ \\
\hline $\mathrm{D}$ & $27,00 \pm 3,03 \mathrm{bB}$ & $39,33 \pm 8,55 \mathrm{aA}$ & $33,17 \pm 8,88$ \\
\hline Total & $33,58 \pm 6,75$ & $33,17 \pm 7,60$ & \\
\hline
\end{tabular}

Médias seguidas de mesma letra minúscula na coluna e maiúscula na linha não diferem entre si pelo teste de Tukey $(\mathrm{P}>0,05)$

A porcentagem média de embriões produzidos in vitro $(33,17 \%)$ foi superior ao resultado apresentado por Bousseau et al. (1998) (17,0\%) quando se utilizou sêmen congelado com diluidor livre de proteína animal.

Nabiev et al. (2003) compararam o uso do diluidor Andromed® com um diluidor à base de Tris e gema de ovo e não observaram diferença estatística no resultado da PIV, corroborando os resultados obtidos no presente experimento. Existem poucos trabalhos na literatura que testaram sêmen congelado com diluidor à base de lecitina de soja na PIV.

Os ejaculados congelados com os diluidores testados obtiveram taxas aceitáveis de clivagem e embriões produzidos in vitro. Mesmo utilizando um método eficiente de seleção espermática in vitro, os processos de fecundação e desenvolvimento embrionário ainda podem ser afetados pelo diluidor do sêmen empregado (Anzar e Graham, 1995).
Na PIV, dois touros (B e C) mostraram melhores taxas de clivagem e produção de embriões quando os ejaculados usados foram diluídos e congelados com o diluidor $\mathrm{A}$, e outros dois touros (A e D) apresentaram melhores resultados com o diluidor $\mathrm{B}$, corroborando os resultados obtidos por Lonergan et al. (1993), que sugeriram uma possível interação entre touro e diluidor utilizado no processamento do sêmen. No entanto, outros estudos ainda devem ser estabelecidos, avaliando-se os fatores individuais com as taxas de clivagem e a produção de embrião, sendo utilizados diferentes diluidores.

No dia nove foi observada a eclosão dos embriões produzidos in vitro. A porcentagem de eclosão (calculada a partir do número de blastocistos obtidos no dia sete) é mostrada na Tab. 5, porém não foi diferente $(\mathrm{p}>0,05)$ entre diluidores e entre os touros.

Tabela 5. Valores médios (x) e desvio-padrão (s) da \% de blastocistos eclodidos em relação ao número de blastocistos no dia sete do sêmen congelado de quatro touros com o diluidor A (Tris e gema de ovo) e o diluidor B (Andromed $®$ - lecitina de soja)

\begin{tabular}{|c|c|c|c|}
\hline \multirow[b]{2}{*}{ Touro } & \multicolumn{2}{|c|}{ Diluidor $(\mathrm{x} \pm \mathrm{s})$} & \multirow[b]{2}{*}{ Total } \\
\hline & $\mathrm{A}$ & B & \\
\hline $\mathrm{A}$ & $77,54 \pm 5,06$ & $77,01 \pm 5,52$ & $77,27 \pm 5,06$ \\
\hline B & $77,92 \pm 5,54$ & $75,19 \pm 2,19$ & $76,55 \pm 4,26$ \\
\hline $\mathrm{C}$ & $75,92 \pm 4,07$ & $77,54 \pm 4,12$ & $76,73 \pm 3,99$ \\
\hline $\mathrm{D}$ & $73,24 \pm 7,82$ & $77,29 \pm 2,31$ & $75,26 \pm 5,89$ \\
\hline Total & $76,15 \pm 5,72$ & $76,76 \pm 3,66$ & \\
\hline
\end{tabular}

Médias seguidas de mesma letra minúscula na coluna e maiúscula na linha não diferem entre si pelo teste de Tukey $(\mathrm{P}>0,05)$.

\section{CONCLUSÃO}

Pôde-se concluir que o diluidor à base de soja pode substituir o composto pelo Tris e gema de ovo, respeitando-se as variações individuais relativas aos touros utilizados no presente experimento. 


\section{REFERÊNCIAS}

AIRES, V.A.; HINSCH, K.D.; SCHLOESSER, F.M. et al. In vitro and in vivo comparison of egg yolk based and soybean lecithin-based extenders for cryopreservation of bovine semen. Theriogenology, v.60, p.269-279, 2003.

AMIRAT, L.; TAINTURIER, D.; JEANNEAU, L. et al. Bull semen in vitro fertility after cryopreservation using egg yolk LDL: a comparison with Optidyl ${ }^{2}$, a commercial egg yolk extender. Theriogenology, v.61, p.895-907, 2004.

ANZAR, M.; GRAHAM, E.F. Effect of filtration on post-thaw quality of bull semen. Theriogenology, v.43, p.439-449, 1995.

ARRUDA, R.P.; CELEGHINI, E.C.C. Validação de técnica para avaliação simultânea das membranas plasmática, acrossomal e mitocondrial de espermatozoides bovinos. Acta Sci. Vet., v.31, p.230-231, 2003.

BLOM, E. The ultrastructure of some characteristic sperm defects and a proposal for a new classification of the bull spermiogram. Nordisk Vet. Med., v.53, p.383-391, 1973.

BOUSSEAU, S.; BRILLARD, P.; MARQUANT-LE GUIENNE, B. et al. Comparison of bacteriological qualities of various egg yolk sources and the in vitro and in vivo fertilizing potential of bovine semen frozen in egg yolk or lecithin based diluents. Theriogenology, v.50, p.699-706, 1998.

BRUM, D.S.; LEIVAS, F.G.; BERNARDI, M.L. et al. Cultivo individual de blastocistos bovinos produzidos in vitro. Braz. J. Vet. Res. Anim. Sci., v.39, p.87-92, 2002.

CARREIRA, J.T. Avaliação da integridade do acrossoma, membrana citoplasmática, cromatina, potencial mitocondrial $e d a$ capacidade de fertilização e desenvolvimento embrionário em FIV de sêmen bovino com altos índices de gota citoplasmática proximal. 2008. 75f. Dissertação (Mestrado) - Universidade Estadual Paulista, Faculdade de Medicina Veterinária e Zootecnia, Jaboticabal, 2008.

CBRA. Manual para exame andrológico $e$ avaliação de sêmen animal. 2.ed. Belo Horizonte: Colégio Brasileiro de Reprodução Animal, 1998. 49p.
CELEGHINI, E.C.C.; ARRUDA, R.P.; ANDRADE, A.F.C. et al. Practical techniques for bovine sperm simultaneous fluorimetric assessment of plasma, acrosomal and mitochondrial membranes. Reprod. Dom. Anim., v.42, p.479-488, 2007.

COELHO, L.A.; ESPER, C.R.; GARCIA, J.M. et al. Fecundação in vitro de oócitos bovinos com sêmen submetido a diferentes diluidores. Rev. Bras. Zootec., v.29, p.397-402, 2000.

COMHAIRE, F.H.; CHRISTOPHE, A.B.; ZAIATA, A.A. The effects of combined conventional treatment, oral antioxidants and essential fatty acids on sperm biology in subfertile men. Prostaglandins Leuk. Essent. Fatty Acids, v.63, p.159-165, 2000.

DELL'AQUA JUNIOR, J.A.; PAPA, F.O.; FREITAS, C.P. et al. Nova proposta de diluidor para semen bovino quimicamente definido. Acta Sci. Vet., v.35, p.1001, 2007.

FUKUI, Y.; KOHNO, H.; TOGARI, T.; HIWASA, M. et al. Fertility after artificial insemination using a soybean-based semen extender (AndromedR) in sheep. J. Reprod. Development, v.54, 2008.

GARNER, D.L.; THOMAS, A.C;. JOERG, H.W. et al. Fluorometric assessments of mitochondrial function and viability in cryopreserved bovine spermatozoa. Biol. Reprod., v.57, p.1401-1406, 1997.

GIL, J.; JANUSKAUSKAS, A.; HAARD, M.Ch. et al. Functional sperm parameters and fertility of bull semen extended in Biociphos-Plus ${ }^{\circledR}$ and Tryladil@. Reprod. Dom. Anim., v.35, p.69-77, 2000.

HERMAN, H.A.; MITCHELL, J.R.; DOAK, G.A. The artificial insemination and embryo transfer of dairy and beef cattle. 8th ed. Illinois: Interstate Publishers, 1996. 382p.

JANETT, F.; FUSCHINI, E.; KEO, S. et al. Comparison of AndroMed ${ }^{\circledR}$ and TRIS-egg yolk extender for cryopreservation of buck semen. Rep. Dom. Anim., v.40, p.356, 2005.

JANUSKAUSKAS, A.; JOHANNSSON, A.; RODRIGUEZ-MARTINEZ, H. Subtle membranes changes in cryopreserved bull semen in relation with sperm viability, chromatin structure, and field fertility. Theriogenology, v.55, p.947-961, 2000. 
LONERGAN, P.; HAFNE, A.L.; FARSTAD, W. et al. Effect of semen extender on in vitro development of bovine embryos following IVF. Reprod. Dom. Anim., v.28, p.174-175, 1993.

MUINO, R.; FERNANDEZ, M.; PENA, A.I. Post-thaw survival and longevity of bull spermatozoa frozen with an egg yolk-based or two egg yolk-free extenders after an equilibration period of 18h. Rep. Dom. Anim., v.42, p.305-311, 2007.

NABIEV, D.; GILLES, M.; SCHNEIDER, H. et al. Comparison of Andromed $\AA$ and Trisegg yolk extender bovine post-thaw sperm function parameters and in vitro fertility. Theriogenology, v.1, p.226, 2003.

NOTHLING, J.O; GERBER, D.; COLENBRANDER, B. et al. The effect of homologous prostatic fluid on motility and morphology of dog epididymal spermatozoa extended and frozen in BiladylR with Equex STMR paste or Andromed $®$. Theriogenology, v.67, p.264-275, 2007.

PACE M.M.; GRAHAM E.F. Components in egg yolk which protect bovine spermatozoa during freezing. J. Anim. Sci., v.39, p.1144-1149, 1974.

PAGL, R.; AURICH, J.E.; MULLERSCHLOSSER, F.; et al. Comparison of an extender containing defined milk protein fractions with a skim milk-based extender for storage of equine semen at $5^{\circ} \mathrm{C}$. Theriogenology, v.66, p.1115-1122, 2006.

SAS Institute Inc. SAS User's guide: statistics. Ver. 9.1.1, SAS Inst., Cary, NC, 2004.

SIQUEIRA, J.B.; GUIMARAES, J.D.; COSTA, E.P. et al. Relação da taxa de gestação com sêmen bovino congelado e testes de avaliação espermática in vitro. Rev. Bras. Zoote., v.36, p.387-395, 2007.
SOUSA, D.B. Viabilidade do sistema Equitainer ${ }^{\circledR}$ na refrigeração do sêmen ovino avaliado pelas análises computadorizada, de microscopia epifluorescente e inseminação artificial. 2002. 103f. Dissertação (Mestrado)Faculdade de Medicina Veterinária e Zootecnia, Universidade Estadual Paulista, Botucatu, 2002.

TARTAGLIONE, C.M.; RITTA, M.N. Prognostic value of spermatological parameters as predictors of in vitro fertility of frozen-thawed bull semen. Theriogenology, v.62, p.1245-1252, 2004.

TEJADA, R.I.; MITCHELL, J.C.; NORMAN, A. et al. A test for the practical evaluation of male fertility by acridine orange (AO) fluorescence. Fert. Steril., v.42, p.87-91, 1984.

THOMSON, L.K; FLEMING, S.D.; AITKEN, R.J. et al. Cryopreservation-induced human sperm DNA damage is predominantly mediated by oxidative stress rather than apoptosis. Human Reprod., v.24, p.2061-2070, 2009.

THUN, R.; HURTADO, M.; JANETT, F. Comparison of Biociphos-Plus ${ }^{\circledR}$ and TRIS-egg yolk extender for cryopreservation of bull semen. Theriogenology, v.57, p.1087-1094, 2002.

UPRETI, G.C.; JENSEN, K.; MUNDAY, R. et al. Studies on aromatic amino acid oxidase activity in ram spermatozoa: role of pyruvate as an antioxidant. Anim. Reprod. Sci., v.51, p.275287, 1998.

WALL, R.J.; FOOTE, R.H. Fertility of bull semen frozen and store in clarified egg yolk Tris-glycerol extender. J. Dairy Sci., v.82, p.817821, 1999. 